The Journal of Engineering and Exact Sciences - JCEC, Vol. 04 N. 02 (2018)

journal homepage: https://jcec.ufv.br

doi: https://doi.org/10.18540/jcecvl4iss2pp0286-0295

OPEN ACCESS - ISSN: 2527-1075

\title{
REFERENTIAL MODEL FOR THE INTEGRATION AND VALIDATION OF OPERATION AND MANAGEMENT INFORMATION IN AN INDUSTRIAL FLUID-PROCESSES ORGANIZATION
}

\section{MODELO REFERENCIAL PARA INTEGRAÇÃO E VALIDAÇÃO DE INFORMAÇÕES DE OPERAÇÃO E GESTÃO DE UMA ORGANIZAÇÃO INDUSTRIALL DE PROCESSOS FLUIDOS}

\author{
M. A. COGHI ${ }^{1}$, I. C. FRANCO ${ }^{2}$ and F. V. DA SILVA ${ }^{1, *}$ \\ ${ }^{1}$ School of Chemical Engineering, University of Campinas (UNICAMP), Campinas, SP, Brazil \\ ${ }^{2}$ FEI University, São Bernardo do Campo, SP, Brazil \\ ${ }^{*}$ Corresponding author. University of Campinas (UNICAMP), School of Chemical Engineering, Campinas, São Paulo, Brazil, Phone: +551935213946 \\ e-mail address: flavio@feq.unicamp.br(F.V.da Silva).
}

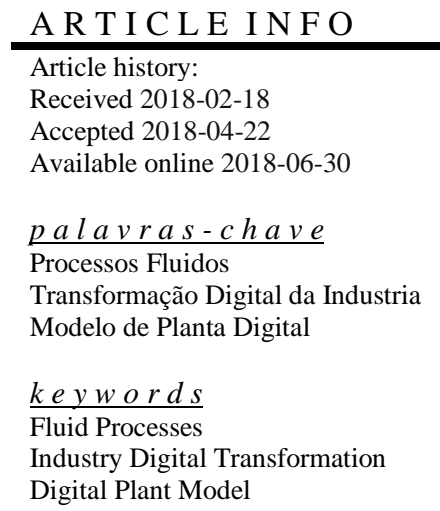

Digital Plant Model

\begin{abstract}
A B S T R A C T
The convergence of AT with IT applied to industrial processes related to manipulating liquids and gaseous materials (fluid processes) is a relevant subject since it shows the benefits that managers will attain by enhancing their decision-making. This work describes an integration architecture of organized information in three different domains: the business, value chain, and asset lifecycle domains, to be used in AT and IT master plans as guidelines for the organization's investment portfolio management. Then a standard model for integration and validation of information concerning operation and management of an industrial organization was developed using industry digital transformation concepts applied to its fluid processes, which was named the Digital Plant model. These results will contribute to the advance of researches related to convergent AT and IT applied in fluid processes, providing decisionmaking managers with greater confidence, formal documentation, and democratization of accumulated experience.
\end{abstract}

R E S U M O

A convergência da Tecnologia de Automação (TA) com a Tecnologia de Informação (TI) aplicada aos processos industriais relacionados à manipulação de líquidos e materiais gasosos (processos fluidos) é um assunto relevante, uma vez que mostra os benefícios que os gestores obterão ao aprimorar sua tomada de decisão. Este trabalho descreve uma arquitetura de integração de informações organizadas em três domínios diferentes: os domínios de negócios, cadeia de valor e ciclo de vida do ativo, para ser utilizada por planos diretores de TA e TI como referência para o gerenciamento de portfólio de investimentos da organização. Um modelo padrão para integração e validação de informações relativas à operação e gerenciamento de uma organização industrial foi desenvolvido usando conceitos de transformação digital da indústria aplicados a seus processos de fluidos, que foi denominado modelo de planta digital. Estes resultados contribuirão para o avanço de pesquisas relacionadas à AT convergente e à TI aplicadas em processos fluidos, proporcionando aos gestores de tomada de decisão maior confiança, documentação formal e democratização da experiência acumulada. 
N O M E N C L A T UR E

\begin{tabular}{|c|c|}
\hline AIMP & Automation and Information Master Plan \\
\hline AM & Alarm Management \\
\hline APS & Advanced Planning and Scheduling \\
\hline AT & Automation Technologies \\
\hline BPM & Business Process Mapping \\
\hline CAD & Computer-Aided Design \\
\hline CAE & Computer-Aided Engineering \\
\hline CAM & Computer-Aided Manufacturing \\
\hline CMM & Collaborative Manufacturing Management \\
\hline CPS & Cyber Physical System \\
\hline DCS & Digital Control Systems \\
\hline DIK & Data, Information, and Knowledge \\
\hline DVR & Data Validation and Reconciliation \\
\hline EAM & Enterprise Asset Management \\
\hline EMI & Enterprise Manufacturing Intelligence \\
\hline ERP & Enterprise Resource Planning \\
\hline IIoT & Industrial Internet of Things \\
\hline IT & Information Technologies \\
\hline KPI & Key Performance Indicator \\
\hline LIMS & Laboratory Information Management System \\
\hline MES & Manufacturing Execution Systems \\
\hline OCAP & Out-of-Control Action Plan \\
\hline OEE & Overall Equipment Effectiveness \\
\hline OLAP & On-Line Analytical Processing \\
\hline OPC-UA & Communications-Unifie \\
\hline & $\begin{array}{l}\text { Architecture } \\
\text { Plant Asset Management }\end{array}$ \\
\hline PAM & Plant Asset Management \\
\hline PFD & Process Flow Diagram \\
\hline PIMS & Plant Information Management System \\
\hline PLC & Programmable Logic Controller \\
\hline PLM & Plant Lifecycle Management \\
\hline PLM/D & Plant Lifecycle Management-Design \\
\hline $\mathrm{PLM} / \mathrm{S}$ & Plant Lifecycle Management-Support \\
\hline PSO & Particle Swarm Optimization \\
\hline RACI & Responsible-Accountable-Consulted-Informed \\
\hline RBAC & Role-Based Access Control \\
\hline RPO & Reactive Power Optimization \\
\hline SCADA & Supervisory Control and Data Acquisition \\
\hline SCM & Supply Chain Management \\
\hline SOA & Service-Oriented Architecture \\
\hline SVG & Scalable Vector Graphics \\
\hline
\end{tabular}

\section{INTRODUCTION}

It is known that the Automation Technologies (AT) and Information Technologies (IT) of the fluid-process industry require monitoring, control, and management of information on their industrial operations, interconnected and published in realtime by their systems, mainly due to seven management needs: 1) synchronization of business with production via certified information; 2) optimization of the supply chain; 3) establishment of collaborative projects and engineering; 4) establishment of an "operator-maintainer" philosophy; 5) creation of value by delegating power to people and measuring their results; 6) prioritization of the customer; and 7) enabling collaboration between all employees of all levels in the hierarchy.

In order to meet these needs, technological cornerstones of Industry 4.0 could be used: augmented reality, autonomous machinery, simulation, vertical and horizontal integration systems, the Industrial Internet of Things (IIoT), 3D printing, cloud computing, cybersecurity, and big data analytics.

The relevance of the digital transformation concepts to humanity is such that in the very near horizon they will change the way in which managers act, although these Cyber Physical System (CPS) integrated technologies are not yet available for their day-to-day tasks.

Several works in the scientific literature indicate the use of industry digital transformation concepts applied to AT and IT convergence in industrial processes related to the handling of solid products for being in this industry the largest applications. Accordingly, in this article it is shown that the fluid processes are also improved by applying industry digital transformation concepts.

As described above, fluid processes are not the largest applications; the industries in this branch are small in number, which limits and restricts the interest in research in this sector. The technologies mentioned, as the technological cornerstones of Industry 4.0 concepts, still need to be studied, researched, and improved so that they can be used in fluid processes.

Regarding IIoT, Atzori et al. (2010) and Xu et al. (2014) cite research results about possible applications of industrial processes for handling solid products, of which the automotive industry is the largest customer. Gubbi et al. (2013) show the vision and architectural elements of the systems and indicate directions that the manufacturing industry ought to follow. Miorandi et al. (2012) present a general overview and suggest what the research-related challenges and applications are. Sadeghi et al. (2015) and Weber et al. (2010) deal with security and privacy concepts of the information gathered and processed by the IIoT in general industries.

Cloud computing, a major technological cornerstone, is cited by Brettell et al. (2014), who show perspectives on how the virtualization, decentralization, and establishment of networks contribute to the change in the industrial scenario. According to Huo et al. (2016), a cloud-based intensive data structure could be applied to diagnosis in fluid industrial processes. Marston et al. (2011) indicate perspectives and discuss how cloud computing will be applied to society in the future. Tao et al. $(2011 ; 2014)$ discuss cloud manufacturing, suggesting the application of the service-oriented manufacturing model to the industry of solid products. Wang et al.(2013) show an interoperable solution for cloud manufacturing applied to robotics and computer integrated manufacturing. Xiong et al. (2015) propose a cloud operating system for industrial applications. Xu (2012) suggest a path from cloud computing to cloud manufacturing with integrations between Computer-Aided Engineering (CAE), ComputerAided Design (CAD), and Computer-Aided Manufacturing (CAM).

The key architecture of cloud computing in generic applications, Service-Oriented Architecture (SOA), is cited by Huhns et al. (2005), who describe its key concepts and principles. Karnouskos et al. (2012) discuss SOA-based architecture for empowering future collaborative cloud-based industrial automation, and Tsai et al. (2010) propose a service- 
oriented cloud computing architecture to be used for general purposes and not only in industry.

With regard to collaborative automation, Busi (2006) cites current integration of information gaps and future research in collaborative performance management. Chen et al. (2010) study distributed collaborative control for industrial automation with wireless sensor and actuator networks. Leitao et al. (2004; 2005) research a collaborative automation approach to distributed production systems and collaborative production automation and control architecture. Ming et al. (2008) show how collaborative process planning and manufacturing are integrated with product lifecycle management. Valilai et al. (2013) study a collaborative and integrated platform to support distributed manufacturing systems using a service-oriented approach based on the cloud computing paradigm. Xiong et al. (2012) present how works in a real-time manufacturing integration and intelligent solution in a global chemical company.

With regard to supply chain management, Frohlich et al. (2001) refer to arcs of integration in an international study of supply chain strategies. Lambert et al. (2000) prefer to focus on issues in the supply chain management of several companies involving multiple members of supply chains, which are then used to illustrate the concepts described. Narasimhan et al. (2002) show the effects of supply chain integration on the relationship between diversification and performance used in integrating a supply chain strategy in the market and product diversification strategy. Vickery et al. (2003) show the effects of an integrative supply chain strategy on customer service and financial performance, showing how to analyze direct versus indirect relationships. Hairui et al. (2008) refer to a multi-agentbased chemical-plant process-monitoring and management system. The application of big data analytics, one of the key pillars of Industry 4.0 concepts, in robotics and solids manufacture was cited by Lee et al. (2014) in service innovation and smart analytics for Industry 4.0 and the big data environment. Lidong et al. (2016) study big data in cyberphysical systems, digital manufacturing, and Industry 4.0. Romero et al. (2016) show what the 4.0 operator will be: human cyber-physical systems and adaptive automation towards human-automation symbiosis work systems.

Towards Industry 4.0, Weyer et al. (2015) show that standardization is the crucial challenge modular, multi-vendor production systems for highly modular, multi-vendor production systems.

Taking into account the described studies, which indicate the application of Industry 4.0 concepts in solids-handling processes, this paper describes a proposal of an integration architecture of information organized in three different domains: the business, value chain, and asset lifecycle domains, to be used in AT and IT master plans as guidelines during the planning period and applied to fluid processes.

\section{TEORY}

\subsection{Gathering and processing data}

The certification and reconciliation of data (Data Validation and Reconciliation - DVR) of industrial balances is constituted of associated information and procedure layers that, among other things, depend on the plant's maturity in diverse aspects, such as its instrumentation.
Practically any level of operational maturity may benefit from the concepts and techniques presented here. An inadequately instrumented plant, or even in design, may benefit from the DVR concepts to direct the investment and plan the instrumentation positioning. This will maximize the valuable information output, while a highly mature plan may experience the maximum gain, obtaining a highly accurate operational picture.

The basis of DVR is access to process data. In an ideal situation, all information must be concentrated in a temporal database (data historian), which is the nucleus of the Plant Information Management System (PIMS).

The balance process data, flow meters and totalizers, data on pressure and temperature, analyzers, and other indirect laboratory measurements, in addition to the manual data input, must be registered in the temporal database by using supervising systems or operational stations of the Digital Control Systems (DCSs), leaving the integrated information to be democratized to the management and making of the users. The DVR is fed by this wide, cohesive, and available data.

\subsection{Data reconciliation}

The unbalances can be fundamentally categorized by their intensity or frequency: small but highly frequent errors are typical of "random errors" inherent in the measurement of any variable and are originated by the superposition of several factors, such as oscillations in the electrical input of the instruments. On the other hand, large and low-frequency errors are called "rough errors".

The most general procedure for data validation is composed of a data pre-conditioning phase (filters, averaging, etc.), followed by an iterative cycle of data reconciliation (mitigation of random errors) and detection/elimination of rough errors, at the end of which, if the conditions allow, more accurate estimates will be provided, that is, estimates that are closer to the "actual" value, with a lower variance and devoid of rough errors. In this article we call this set of procedures DVR.

The data reconciliation essentially has a need for redundancies in the process readings, and the analysis of the existing measurers positioning is an important tool to guide investments in automation. Inadequately instrumented plants with low redundancy or badly integrated architectures offer fewer possibilities for data reconciliation and detection of rough errors.

The classical data reconciliation procedure is based on adding information that is considered perfect regarding the conservation of mass and energy and often kinetic and thermodynamic models.

Another fundamental piece of information to be taken into account is the process topology, represented in a Process Flow Diagram (PFD), which introduces the system's restrictions, basically mapping the sources and the destinations of the mass and energy in all circuits.

It is also necessary to gather the available information about the reading precision in a variance matrix. This information makes it possible to perform larger adjustments for the least reliable readings and vice-versa, preserving the quality of the measuring equipment.

In the example illustrated by Figure 1, all flow rates are 
measured by instruments. It is possible to verify that there are two readings for each flow rate: $\mathrm{F} 3$, for example, has a value read by an instrument and can be calculated by using F3 $=\mathrm{F} 1$ F2.

In case F3 is not measured, it is not possible to verify it, because the $\mathrm{F} 3$ flow rate will only be calculated and not directly measured. The data reconciliation uses mathematical methods to divide the general estimation problem into subproblems: redundant, not redundant, observable, and not observable. This is done in such a way as to obtain estimates for the measured values that are redundant and for the non-measured values that are observable, so that the balancing equations are respected.

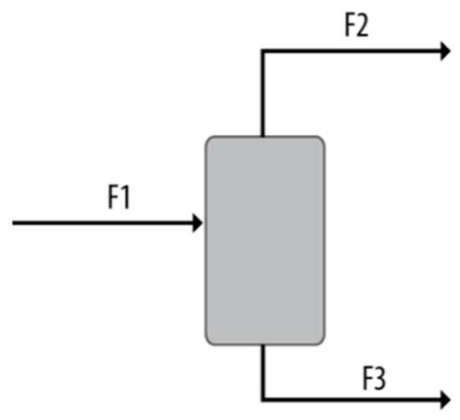

\section{Figure 1 - Measurement points of all inputs and outputs units}

Numerous software tools can be used by a DVR system: from a solver in an Excel file to specific systems that execute models and interpret its generated results automatically.

\subsection{Detection and correlation of rough errors}

Errors that cannot be mitigated by data reconciliation procedures due to their intensity and frequency could have several origins: complete failures in reading (outliers e.g. spurious values), undetected leakage and evaporation losses, fouling of the heat exchanger, decalibrated or unreset instruments, sensor failures, manual withdrawal or addition of material to the process without informing the system, and alignment issues in transfer routes, among others.

The detection and identification of rough errors is an important tool for preventive and corrective maintenance of equipment and sensors. The technique makes it possible to follow the detection history, even with an approximated precision in the positioning, which may indicate which equipment and sensors are in a state of progressive or constant failure.

The basis for rough error detection is statistical tests. A simple method applied in the detection of these errors by a DVR is to perform a residue test on the reconciled measurements in search of large errors, that is, a value that does not fit a given probability distribution. The test's algorithm analyzes the residues of the reconciled measurements by comparing a statistical index with a critical value.

An index larger than the critical value implies a rough error between the readings. The algorithm is executed until all the measurements show error indices that are smaller than the critical value. In which case the system is then considered deprived of rough errors and a final reconciliation procedure must be performed in the DVR cycle.

\subsection{Reports Emission}

The results of the procedures performed by the DVR must be disclosed to all licensed and interested individuals via the Intranet. The opening of the production accountability process is essential to validate the process and the results and to facilitate the effective acceptance by all users.

If this process is not implemented, the official and the particular results of areas, operators, and managers will still be obtained, but in an individual manner, so that the gains are neither perceived nor used.

\subsection{Data quality analysis}

From the balancing results, it is possible to plot a trend graph in the temporal database showing the evolution of the unbalances and of the correlations applied to the measurements. This procedure is useful to verify whether the unbalance in a given process knot have anomalous behavior or not. A natural behavior would be small and random-sign deviations in the unbalances and in the corrections applied to the measurements. Any pattern that is not random must be thoroughly examined.

An alternative is to monitor the quality indices capable of expressing, in a single percentage value, the factors that determine the data quality and that were estimated by the DVR. This would provide a higher homogeneity in the analysis, since these indices would be applicable to any kind of measure of the process. Actions considered fundamental to the success of the project implementation involving DVR systems as the nucleus of the digital plant model proposed in this article are as follows:

Daily reconciliation: The reconciliation cannot be a sporadic procedure but must be a routine closing ritual for all the calculations of the individual plant's performance and production accountability. A one-day interval is the most well recommended frequency of evaluation. Partial results by shift can be used to detect issues in a more immediate manner. A routine of data validation and solving discrepancies must be established.

Dedicated personnel: The balance activity cannot be delegated to administrative assistants. This activity must be performed by a specialist and requires expertise in the process. The goal of reconciliation is not only to provide the correct numbers but also to scrutinize the results and look for the causes of the detected nonconformities. In several organizations, this routine is executed by personnel who are less apt to judge the consequences of an unexpected result and several corrective actions may be left unexecuted. With the evolution of technology, "specialist" systems could perform this task, scrutinize the system status, and recommend actions themselves. Another observed route is to meet this need via Web services available on the IIoT.

Strategy for solving data discrepancies: When the balance result contains surprises, such as large unbalances in one or more knots and/or corrections applied to readings out of stochastic equilibrium, corrective actions must take place. The rough error analysis provides the opportunity to detect leakages, overflows, damaged or decalibrated instruments, manual withdrawals not mapped in the material's system, and other events or situations of nonconformity.

Communication of results: The DVR results must be available to all departments for use in performance reports, production, and so on by means of their publication in the PIMS. 
As in the digital plant model, the data is democratized by the PIMS, so that operators, managers, or production/process engineers will have exactly the same version of the resulting information for a given shift, day, or month.

\subsection{Requirements of a DVR system}

A satisfactory DVR system must present the following properties: I) It must be capable of automatically acquiring data from any data source: Programmable Logic Controller (PLC), Supervisory Control and Data Acquisition (SCADA), DCS, Laboratory Information Management System (LIMS), or a temporal database. The ideal case is when the DVR is an Open Platform Communications- Unified Architecture (OPC-UA) client, able to automatically search data in any server of this kind. II) It must possess a process diagram editor of a graph editor for inputting the plant's topology. Accordingly, process engineers will be able to configure this system quickly and handle it easily. III) It must be able to export data to Excel for report elaboration. IV) It must be able to publish data on the organization's intranet. V) It must be able to store the reconciled data history on the temporal data base server. VI) It must be able to provide indices of data quality that allow evaluation of the measurements independently of their scale, engineering unit, or origin. In other words, the system must be capable of sorting the data quality by, for example, grading it from 0 to $100 \%$. VII) It must be able to perform the data quality analysis on the temporal database itself. Some software applications on the market have extra built-in tools such os systems specializing in data validation and result analysis.

\section{METHODOLOGY}

Clusters of Data, Information, and Knowledge (DIK) are becoming larger and more present in our lives and, consequently, in the daily activities of industry professionals. These professionals who must manage them in order to maximize their benefits in decision making, for example, to contain the corporate knowledge and to democratize and distribute it to their resources at the right times, aiming at increasingly aggregating value to the business. Nevertheless, the high accumulated growth rate of DIK in industries has a few consequences: a need for mobility of human resources, especially those related to high-level administration; reduction of the number of personnel from the operational to the corporate level; growth in demand for increasingly specialized services; and virtualization of computer hardware.

Management of the industrial operation and execution; management of information concerning laboratories, supply entry, products in process, and finished products; management of managing costs, finances, resources, and administrative and commercial process operations; simulation, optimization, and advanced control ; management of maintenance and engineering; management of maintenance and company assets; management of the industrial efficiency and performance via Web portals, which, among others, are also subject to changes. These systems will be installed and marketed by cloud computing, as a consequence of computer virtualization, Service-Oriented Architecture (SOA), Software As A Service (SaaS), wearables, the IIoT, big data analytics, cyber security, and Collaborative Manufacturing Management (CMM) into reality.

Before the transition from information to knowledge, the shop floor data requires certification with regard to its veracity and integrity. We add to these information fluxes the concept that: It is no use getting informed if one is not sure about the information source or about the information's veracity. With that being said, it is no use implementing investments in Web services, SOA, SaaS, and wearables that establish specialist systems for plant operation management, before validation it, certifying where each part of information is generated in the online energy-mass balance of an industrial plant. Services and functions incorporated via software in the fluid-handling industries, such as Advanced Planning and Scheduling (APS), transport logistics and Supply Chain Management (SCM), and compaction of historical information and knowledge management (PIMS).

It is desirable that the inventory values and the industrial plant's activities and stock and yield accounting are based on data that complies with the known restrictions in the process (mass-energy balance); that is, they must be reconciled data. The basic principle of a mass-energy balance is the law of conservation of matter and energy, which forces the total input rate to be equal to the total outcome rate, subtracting the amount that has been kept in the process.

In practical terms, its not verified due to problems such as errors in measurements and signal transmission, poor conditioning of the measuring instruments, leakages, evaporation losses, equipment inefficiency, and so on. For this reason, actions must be taken to fix these problems. In order to do so, four steps are adopted, often cyclically: Step 1) gathering and processing data; Step 2) reconciling the resulting data; Step 3) detecting, analyzing, and fixing rough errors, and Step 4) elaborating reports and communicating the results.

The referential Digital Plant model (Figure 2) presented here propose the integration and intelligence to the AT and IT systems of industrial fluid processes. The Digital Plant integrates the business information domain with another two domains, the value chain domain and the organization's assets lifecycle domain, in order to enhance the knowledge management and real-time collaboration among all corporate systems.

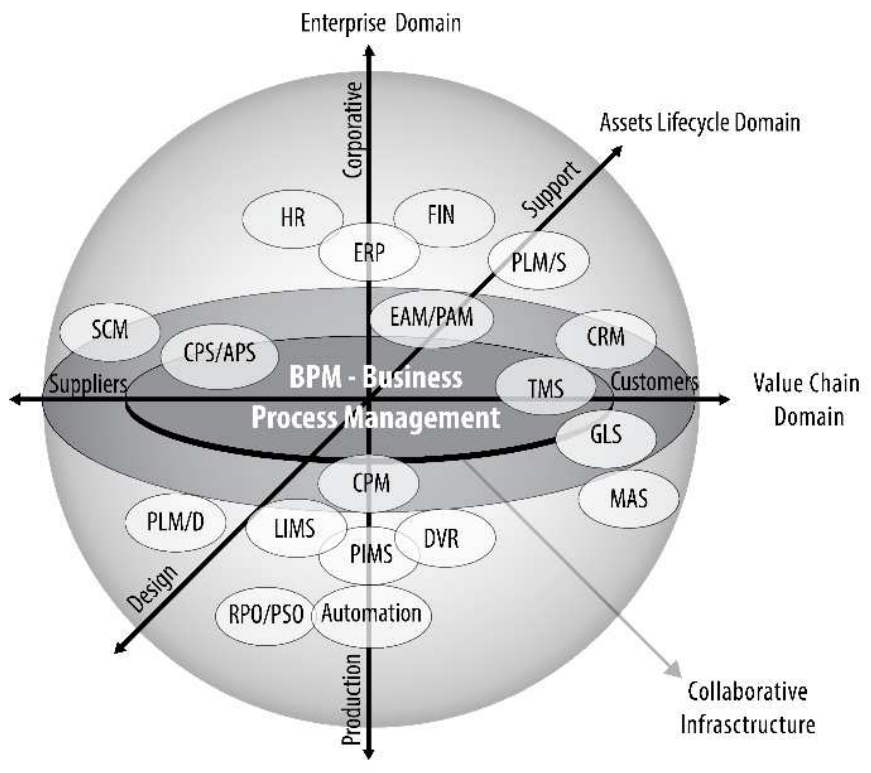

Figure 2 - Digital Plant model

The model presented here is not intended to be a 
universal proposal of integration for all possible market solutions, as it was developed to serve as a basis for creating automation and informatics directive plans with the following requirements: synchronization of the business with the production via certified information; optimization of the supply chain; implementation of the collaborative project and engineering; establishment of the "maintainer-operator" philosophy; generation of value by measuring results and delegating power to personnel; and prioritization of the customer and enablement of collaboration by means of Web services.

Table 1 - Integration of the information needs in fluid processes.
Once the conception requirements are fulfilled, the model may still serve in the future as a base for the development of several other integration proposals that use systemic solutions that meet the commonly required needs of the chemical industry or correlated processes.

The CMM model was adopted as inspiration for the Digital Plant model. Digital Plant integrates the information needs presented in Table 1 and is adequate for application in industries that process fluid products.
Information Axis

[a] Domain: Business

[b] Domain: Value Chain

\section{Reference to the following activities}

- Mapping investment needs regarding instrumentation, Network, SCADA, DCS, etc;

- Integration of the instrumentation, control, supervision, and industrial management systems as well as the applications for Particle Swarm Optimization (PSO) and Reactive Power Optimization (RPO).

- The architectures of the networks that will integrate the sensors, instruments, valves, remote stations, controllers, interfaces, and operation stations;

- In order to integrate the PIMS and DVR information where data and industrial information are concentrated, validated and shared;

- Mapping, storing and managing information presentation needs, planning the gathering, storage, and democratization of the industry's information;

- Transforming historical information into continual enhancement in the production, process, quality, maintenance, and operation of human resources in shifts;

- Monitoring management costs, quality, traceability, and genealogy of the products circulating in the industry;

- Integrating the information from the laboratories that analyze suppliers and production;

- Integration with Manufacturing Execution Systems (MES) and other functions, such as Overall Equipment Effectiveness (OEE), Alarm Management (AM), genealogy and traceability, down-time operations, etc.

- Integration of SCM applications, management of suppliers of raw material and transportation logistics, processes of control of balance of raw material tanks by suppliers integrated in real time with the needs of the industry;

- Integration with resource planning, planning and advanced production control applications.

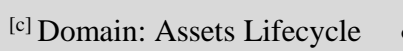

- Mapping the need for integration between engineering information, equipment data sheets, mesh diagrams, process and instrumentation diagrams via Plant Lifecycle Management (PLM) applications, before the operation (Design - PLM/D), as well as during it (Support - PLM/S);

- $\quad$ Mapping Plant Asset Management (PAM) and Enterprise Asset Management (EAM) needs.

\footnotetext{
[a] Information ranging from shop floor data will lead to the aggregation of value through its real time integration with other applications and will inform stationsworks whose users are managers, directors, and the CEOs;

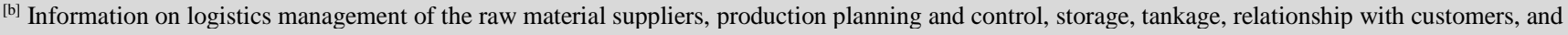
management of delivery trucks who take the finished products to the customers;

${ }^{[c]}$ Information on the equipment design and remaining industrial assets and their maintenance during the operation.
}

The main motivation for developing the Digital Plant model is related to the specific needs pertaining to fluid processes: a certification of the process readings in order to satisfy mass-energy balances before integrating them with the corporate information for knowledge and decision-making. As a consequence, DVR-associated PIMS will have a distinctive role and can be called the Digital Plant's core, because investments are made every moment in a corporate world, but professionals are not attentive to the needs concerning knowledge and information certification before connecting the industrial to the business world.

\section{RESULTS AND DISCUSSION}

As stated, the Digital Plant's core is the association of PIMS and DVR, whose function is to calculate and manage the online mass-energy balance, assuring the validation and certification of information that will compose several management parameters. These parameters as: such as real-time management costs, a better set of production information, efficiencies, performances, planned versus accomplished, veracity of information that certifies the quality of the products produced or acquired from suppliers, the accuracy of the measuring and controlling instrumentation, and so on.

\subsection{Management indicators}

Besides the integration of technologies and collaboration among the information domains, the Digital Plant provides a scheme for organizing management indicators. Indicators must be sorted by a formal and methodical process for a drill-toanywhere analysis. In order to clarify this claim, it is necessary to return to the most basic definition of information.

Information is an answer to a question. The question arises first. In order to determine which are the main required 
indicators for the decision-making process, one must understand how each decision is taken and what information is needed, for the manager to apply a suitable action following notification about an issue. For example, if one needs to know whether an operational asset (reactor, filter, mill, distillation column) is being used well, one needs to measure all the process stops, the performance or production rate with respect to the nominal value for which the process was specified (according to specifications), and the quality of the generated product. Afterwards, it is customary to multiply these three indicators to create a Key Performance Indicator (KPI) named called the OEE.

The OEE indicator displays how the production potential of an asset is being used. As an example, if the industrial organization has bought a new gas washing column for acetone recovery, with a given nominal recovery level, one ought to know how much acetone is effectively being extracted from this column (a process asset that was acquired some time ago by a monetary investment).

In the column's stoppages, its performance drops with respect to the nominal values, and the losses of quality have a bad effect on this grading. If the grade is 0.90 , one can assert that the column is being used at $90 \%$ of its potential performance. If this grade becomes lower, on a given day, it is necessary to decompose this indicator into its components, and if the problem is the column's availability, the main causes for the stoppages must be understood and tackled. This unfolding process for the detailing of causes is called drill-to-anywhere analysis and is performed as a second step after the problem's detection.

First, the problem is detected by the dashboard's visualization tools; then, the manager in charge runs an investigation or problem diagnosis using another set of dashboard tools, for example Pareto charts of the stops stratified by the magnitude of the cause. Summarizing, the decisionmaking process must be simulated during the definition of the KPI in order to assure its usefulness and appropriateness in evidencing a given issue in the organization.

In order to check whether a certain KPI is indeed useful, we must verify which business matter it is related to, what question it answers, and what needs to be done if its value is incompatible with a settled goal.

Determining which action plan to take in any operational situation is an arduous task that requires much investigation. Often, it is known how to detect a problem but not how to fix it. Evidently, much can be learned about process behavior by investigating the indicator's system. This will keep on refeeding a continual re-examination of the action plan. The Outof-Control Action Plan (OCAP) techniques, recommended by the Six Sigma methodology, are very useful in this continual reexamination.

Among the calculated indicators, a few are technical and operation-related. For example, for each of the plant's control meshes, about 40 indicators show whether the controller is operating well. From these indicators, about four or five may provide a global performance KPI of the mesh to be monitored. What the asset management needs to know is whether or not a certain controller obeys the commands given.

\subsection{Management information visualization techniques}

The display of a management indicator in the Digital Plant model must happen in a clear manner so as to facilitate the observation of its normal or abnormal behavior, and it must be insight-stimulating. The components must be shown for the exhibition of individual, grouped, and large data collections. The presentation components must be chosen for their ease of learning and use by users and for their adaptability to the business. In industrial environments, the visual components are useful for planning and process-monitoring purposes, identifying anomalies and deviations, and analysis.

The Digital Plant model must be developed in this environment, because it possesses several advantages: it is suitable for SOA (Web service architectures and application marketplace), it facilitates maintenance, because it concentrates the applications in one or only a few servers, and the software performs updates, facilitates access control, and improves security via cybersecurity.

The improvement of the components' presentation was the missing element that will enable this technology to substitute for the inherited system designed to work in traditional desktop environments. These visual components contribute significantly to enabling this substitution to occur with an improvement of quality for the final user.

As a practical example, a screen produced by a PIMS system, using Scalable Vector Graphics (SVG), may be imported directly via the Web portal to be displayed as a component in a smartphone. This technology enables a single screen to display any factory system, avoiding a multiplicity of monitor screens, which require a physical room in the plant.

The resources proposed by the Digital Plant model, used to represent information for the staff of the local or complete corporation group management, are proposed in Figures 3-5. The resources and their descriptions are presented in Table 2.

Table 2 - Resources proposed by the Digital Plant model and their descriptions

\begin{tabular}{lll}
\multicolumn{1}{c}{ Resource } & \multicolumn{1}{c}{ Description } & Figure \\
\hline Treemaps & $\begin{array}{l}\text { Used to display information } \\
\text { associated with hierarchic structures } \\
\text { for the plant overview, industrial } \\
\text { assets status, control mesh tuning, } \\
\text { etc. }\end{array}$ & Figure 3A \\
\hline $\begin{array}{l}\text { Management } \\
\text { alarms }\end{array}$ & $\begin{array}{l}\text { These are generally hierarchy } \\
\text { diagrams. They enable a presentation } \\
\text { devoid of any identified anomaly and } \\
\text { are frequently used in industrial } \\
\text { operation environments as a } \\
\text { management tool. }\end{array}$ & \\
\hline Scale charts & $\begin{array}{l}\text { The values of the process variables } \\
\text { may be monitored continually in } \\
\text { these components until a given limit } \\
\text { is reached and a management alarm } \\
\text { is generated. They are used often in } \\
\text { anomaly identification due to their } \\
\text { clarity and simplicity. }\end{array}$ & \\
\hline
\end{tabular}




\section{Table 2: Continued}

\begin{tabular}{|c|c|c|}
\hline $\begin{array}{l}\text { Corporate } \\
\text { charts }\end{array}$ & $\begin{array}{l}\text { Bar charts are the most common. } \\
\text { Although they reproduce a limited } \\
\text { amount of information, the } \\
\text { visualization is simple and direct. } \\
\text { Also, they can be used as filters in } \\
\text { other charts for a drill-to-anywhere } \\
\text { analysis. The Pareto charts display } \\
\text { the causes of a phenomenon ranked } \\
\text { by their relevance. }\end{array}$ & Figures 3E,F \\
\hline Pie charts & $\begin{array}{l}\text { These are good for showing the } \\
\text { participation of up to six variables. In } \\
\text { order to compare the influence or } \\
\text { participation of a larger number of } \\
\text { elements, histograms are more } \\
\text { suitable. }\end{array}$ & Figure $3 \mathrm{G}$ \\
\hline $\begin{array}{l}\text { Tracking } \\
\text { diagrams }\end{array}$ & $\begin{array}{l}\text { These represent and search for the } \\
\text { materials used in the manufacture of } \\
\text { an intermediate product and their use } \\
\text { in the manufacture of other } \\
\text { intermediate or final products }\end{array}$ & Figure 4A,B \\
\hline
\end{tabular}

Management One can generate a large amount of trends management information from the analysis of dimensions (the manner in which the data is analyzed) with the measurements (analysis target value or quantity), for example the volume of operations; average incoming and outgoing deliveries; quantity of manual interventions; quality/conformity indices and percentage usage of the operational capacity. The possibilities are abundant if we consider that the dimensional modeling allows us to cross data of any dimension with any available measurement.

Pivot tables These enable the exchange of lines for reports for columns and the representation of multidimensional cubes in two dimensions. They may use the OnLine Analytical Processing (OLAP) tool, which is frequently used by business intelligence systems;

\begin{tabular}{lll}
$\begin{array}{l}\text { Bubble } \\
\text { charts }\end{array}$ & $\begin{array}{l}\text { These are the visual representation of } \\
\text { the relationships found by data } \\
\text { mining tools, enabling the } \\
\text { investigation of cause-effect } \\
\text { relationships among the process } \\
\text { variables. }\end{array}$ & \\
& $\begin{array}{l}\text { Among the numerous types of } \\
\text { existing charts, these stand out as one } \\
\text { of the most widely used for real-time } \\
\text { planning and monitoring of } \\
\text { production. The use of drag and drop } \\
\text { resources allows the production } \\
\text { orders to be visually sequenced on } \\
\text { the dashboards. }\end{array}$ & \\
\hline $\begin{array}{l}\text { Gantt } \\
\text { diagrams }\end{array}$ & $\begin{array}{l}\text { These show the strategies unfolding } \\
\text { into perspectives and action in real- }\end{array}$ & \\
& Figure 5 \\
\hline $\begin{array}{l}\text { Strategic } \\
\text { maps }\end{array}$ & & \\
\hline
\end{tabular}

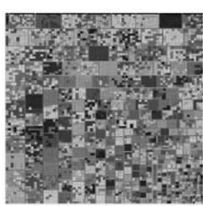

(A)

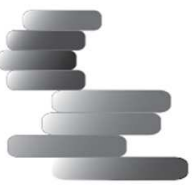

(E)

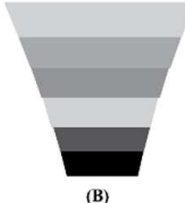

(B)

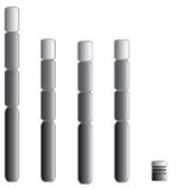

(F)

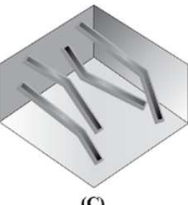

(C)

(D)

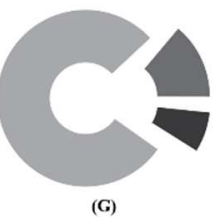

(G)

Figure 3 - Digital Plant information: A) treemaps; B) management alarms; $C$ and $D$ ) scale charts; $E$ and $F$ ) corporate graphs; G) pie charts

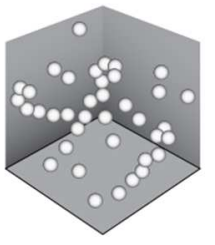

(A)

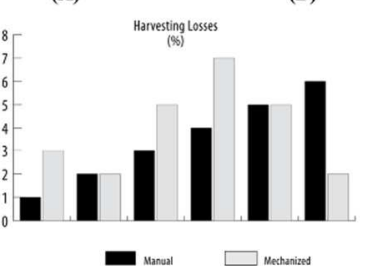

(D)

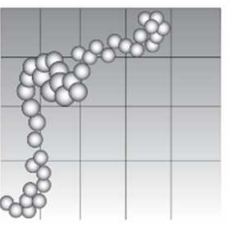

(B)

Orders Monitor

- $1 \ldots 1 \ldots 1$ I

(F)

Figure 4 - Digital Plant information: A and B) tracking diagrams and correlation charts; $C$ ) management trends; D) pivot tables for reports; E) bubble chart; and F) Gantt chart

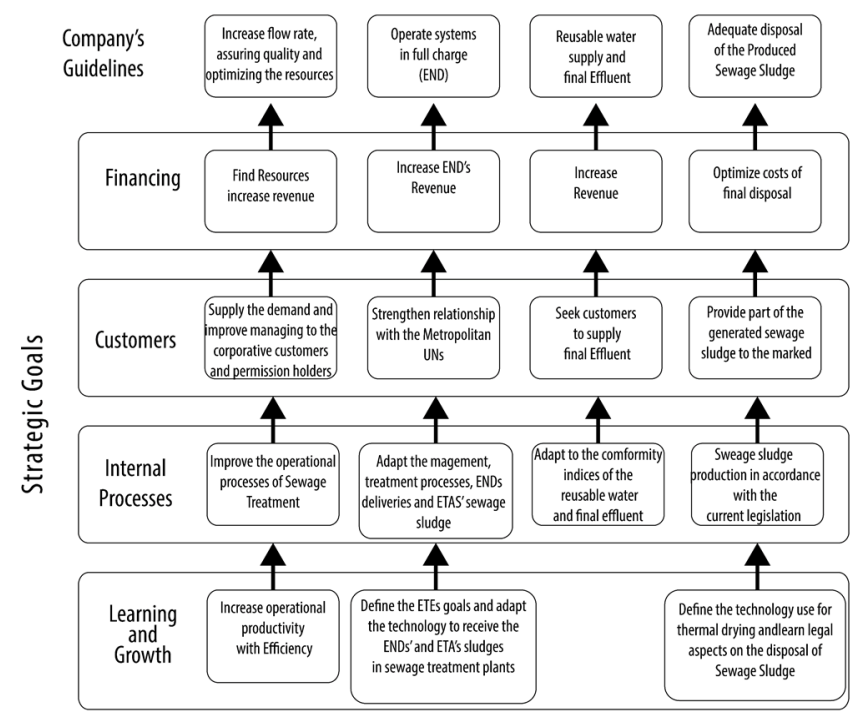




\subsection{Integrating information towards knowledge management}

The Digital Plant's library dashboards are not merely a layer of representation with graphical component collections. They are essential for aggregation and integration; they aggregate content and integrate areas and processes.

The dashboards provide abstraction from the information (application) sources, silos, organizational structures, and even companies. The idea is to supply the required information for the decision-making independently of the information's origin. For example, the production programming of the day comes from the APS, production results of the day, and production indicators, given by the MES, the current line's velocity, provided by the PIMS, dollar exchange rates and commodity stocks, found in external sources, and the order's status, given by the Enterprise Resource Planning (ERP). Consequently, a need for integration with several different and scattered information sources of diverse technologies arises.

Due to its complexity, the integration aspect is one of the most critical factors in the dashboard's implementation. Luckily, several efforts are being made in order to solve the integration difficulties and issues, especially by creating and applying the SOA.

The service bus has an important role in the implementation of the dashboards. It serves as a mediator between the customers and the available services. Its main goal is to provide an abstraction of the information's origins, allowing all the information usage to be developed and managed with the highest possible independency from the infrastructure, systems, protocols, and proprietary technologies. All of the integration is performed through the consumption of the available services in the bus, not necessarily the system's specific services. The information flux is simplified and the control of the integration environment is wider, in addition to enhancing the reuse of services. The so-called Enterprise Manufacturing Intelligence (EMIs) are a category of systems available on the market for the operational dashboard implementation.

Another fundamental Digital Plant component for an EMI solution is a framework for dashboard implementation. The user interface must be web-based, allowing easier access to the dashboards. In addition, it must enable access based on RoleBased Access Control (RBAC)-like rules, an access control based on papers, where it is possible to create, for example, specific visions for the plant's production manager, a specific area manager, the production supervisor, or an operator of a line according to their information needs in each of these positions. Since the dashboards are implemented from a standard integration infrastructure that aims at the reuse of services (service bus), the presented information, for both the manager and the line operator, must be coherent and originated by the same source, assuring an alignment between the operation and management visions.

\subsection{Involving the manager}

Once the dashboard's content and its information representation have been defined, it must be ensured that all the cycles, notifications, perceptions, diagnoses, and actions are being performed. This cannot be achieved without a governance study. In this study, for each dashboard function related to the operation's multiple dimensions, namely energy, quality, inventory, production, process, asset management, and so on, it must be determined which functions are responsible for the analysis of the indicator in question, the decision-making, and the effective operational action. Every link of this chain must be informed about its responsibilities and must be trained.

There are many methodologies for guiding this work, such as the definition of an Responsible-AccountableConsulted-Informed (RACI) responsibility matrix. Finally, whether the action plans for the beginning of the dashboard operation tasks are well defined must be verified, and then the whole of the operation's development, including the notifications of the detected abnormalities and the applied corrective actions, must be documented. From the study of these records, better guidelines will be created to be incorporated in the procedures. Without fixing this link, the management is not complete and the results are not achieved.

\section{CONCLUSION}

The Digital Plant model was born from the need for a referential architecture for the Automation and Information Master Plan (AIMP) in industrial fluid-process organizations. The automobile sector, as the major customer of equipment and automation solutions, already possesses the CMM, which is impossible to use in processes of continual production flux such as the fluid processes of industrial organizations.

This scenario requires the idealization, before everything, of a tactical plan based on the investor company's strategic needs. An AIMP integrated in the strategic planning of this organization will determine baselines to formalize what to do the budget, which is the best/most urgent project, how to do it, where to do it (department or company in a group), when, and why (metrics and justifications for measuring results after the investment), using a referential model as a guide throughout.

\section{R E F E R E N C E S}

ATZORI, L., IERA, A., MORABITO, G. The Internet of Things: A survey. Comput. Netw. 2010, 54(15):27872805.

BRETTELL, M., FRIEDRICHSEN, N., KELLER, M., MARIUS ROSENBERG, M. How virtualization, decentralization and network building change the manufacturing landscape: An Industry 4.0 perspective. Int. J. Mech. Aerosp. Ind. Mechatron. Manuf. Eng. 2014, 8(1): 37-44.

BUSI, M. Collaborative performance management: present gaps and future research. Int. J. Prod. Perf. Manag. 2006, 55(1):7-25

CHEN, J., CAO, X., CHENG, P., XIAO, Y., SUN, Y. Distributed collaborative control for industrial automation with wireless sensor and actuator networks. IEEE Trans. Ind. Electron. 2010, 57(12):4219-4230.

FROHLICH, M. T., WESTBROOK, R. Arcs of integration: an international study of supply chain strategies. J. Oper. Manage. 2001, 19(2):185-200.

GUBBI, J., BUYYA, R., MARUSIC, S., PALANISWAMI, M. Internet of Things (IoT): a vision, architectural elements, and future directions. Future Gener. Comput. Syst. 2013, 29(7):1645-1660.

HAIRUI, W., YONG, Z. Multi-agent based chemical plant process monitoring and management system. In: $4 \mathrm{TH}$ 
INTERNATIONAL CONFERENCE ON WIRELESS COMMUNICATIONS, NETWORKING AND MOBILE COMPUTING (WICOM), Oct. 12-14, 2008, Dalian, China, 1-4.

HUO, Z., MUKHERJEE, M., SHU, L., CHEN, Y., ZHOU, Z. Cloud-based data-intensive framework towards fault diagnosis in large-scale petrochemical plants. In: $12 \mathrm{TH}$ INTERNATIONALWIRELESS COMMUNICATIONS AND MOBILE COMPUTING CONFERENCE, Sept. 5-9, 2016, Paphos, Cyprus, 1080-1085.

HUHNS, M. N., SINGH, M. P. Service-oriented computing: key concepts and principles. IEEE Internet Comput. 2005, 9(1):75-81.

KARNOUSKOS, S., COLOMBOT, A. W., BANGEMANN, T., MANNINEN, K., CAMP, R., TILLYII, M., STLUKA, P., LAMMESTT, F., DELSINGU, J., ELIASSON, I. A SOA-based architecture for empowering future collaborative cloud-based industrial automation. In: 38TH ANNUAL CONFERENCE ON IEEE INDUSTRIAL ELECTRONICS SOCIETY-IECON, Oct. 25-28, 2012, Montreal, Canada, 5766-5772.

LAMBERT, D.M., COOPER, M.C. Issues in supply chain management. Ind. Market. Manag. 2000, 29(1):65-83.

LEE, J., KAO, H. A., YANG, S. Service innovation and smart analytics for Industry 4.0 and big data environment. Procedia CIRP, 2014, 16, 3-8.

LEITAO, P., COLOMBO, A.W., RESTIVO, F.J., SCHOOP, R. Collaborative automation approach to distributed production systems. In: 2ND IEEE INTERNATIONAL CONFERENCE ON INDUSTRIAL INFORMATICS, June 24-26, 2004, Berlin, Germany, 27-32.

LEITAO, P., COLOMBO, A.W., RESTIVO, F.J. ADACOR: a collaborative production automation and control architecture. IEEE Intell. Syst. 2005, 20(1):58-66.

LIDONG, W.L., WANGB, G. Big data in cyber-physical systems, digital manufacturing and Industry 4.0. Int J Precis Eng Manuf. 2016, 6(4):1-8.

MARSTON, S., LI, Z., BANDYOPADHYAY, S., ZHANG, J., GHALSASI, A. Cloud computing - the business perspective. Decis. Support Syst. 2011, 51(1):176-189.

MING, X.G., YAN, J.Q., WANG, X.H., LI, S.N., LU, W.F., PENG, Q.J., MA, Y.S. Collaborative process planning and manufacturing in product lifecycle management. Comput. Ind. 2008, 59(2-3):154-166.

MIORANDI, D., SICARI, S., PELLEGRINI, F., CHLAMTAC, I. Internet of Things: vision, applications and research challenges. Ad Hoc Networks, 2012, 10(7):1497-1516.

NARASIMHAN, R., KIM, S. W. Effect of supply chain integration on the relationship between diversification and performance: evidence from Japanese and Korean firms. J. Oper. Manage. 2002, 20(3):303-323.

ROMERO, D., BERNUS, P., NORAN, O., STAHRE, J. The Operator 4.0: human cyber-physical systems \& adaptive automation towards human-automation symbiosis work systems. In: ADVANCES IN PRODUCTION MANAGEMENT SYSTEMS- APMS: INITIATIVES
FOR A SUSTAINABLE WORLD, Sept. 3-7, 2016. Iguassu Falls, Brazil, 677-688.

SADEGHI, A. R., WACHSMANN, C., WAIDNER, M. Security and privacy challenges in industrial Internet of Things. In: 52ND ANNUAL DESIGN AUTOMATION CONFERENCE, June 7-11, 2015, San Francisco, USA.

TAO, F., ZHANG, L., VENKATESH, V. C., LUO, Y., CHENG, Y. Cloud manufacturing: A computing and service-oriented manufacturing model. Proc. Inst. Mech. Eng. Part B J. Eng. Manuf. 2011, 225(10):1969-1976.

TAO, F., ZHANG, L., CHENG, Y., XU, L. D., LI, B. H. CCIoTCMfg: Cloud computing and Internet of Things-based cloud manufacturing service system. IEEE Trans. Ind. Inf. 2014, 10(2):1435-1442.

TSAI, W., SUN, X., BALASOORIYA, J. Service-oriented cloud computing architecture. In: $7 \mathrm{TH}$ INTERNATIONAL CONFERENCE ON INFORMATION TECHNOLOGY, Apr. 12-14, 2010, Las Vegas, USA, 684-689.

VALILAI, O. F., HOUSHMAND, M. A collaborative and integrated platform to support distributed manufacturing system using a service-oriented approach based on cloud computing paradigm. Rob. Comput. Integr. Manuf. 2013, 29(1):110-127.

VICKERY, S. K., JAYARAM, J., DROGE, C., CALANTONE, $R$. The effects of an integrative supply chain strategy on customer service and financial performance: an analysis of direct versus indirect relationships. J. Oper. Manage. 2003, 21(5):523-539.

WANG, X. V., XU, X. W. An interoperable solution for cloud manufacturing. Rob. Comput. Integr. Manuf. 2013, 29(4):232-247.

WEBER, R. H. Internet of Things - new security and privacy challenges. Comput. Law Secur. Rep. 2010, 26(1):2330.

WEYER, S., SCHMITT, M., OHMER, M., GORECKY, D. Towards Industry 4.0 - standardization as the crucial challenge for highly modular, multi-vendor production systems for highly modular, multi-vendor production systems. IFAC-PapersOnLine, 2015, 48(3):579-584.

XIONG, G., JI, T., ZHANG, X., ZHU, F., LIU, W. Cloud operating system for industrial application. In: $10 \mathrm{TH}$ IEEE INTERNATIONAL CONFERENCE ON SERVICE OPERATIONS, LOGISTICS, AND INFORMATICS, Aug. 19-21, 2015, Tunis, Tunisia, 4348.

XIONG, G., NYBERG, T. R., WANG, F. Real-time manufacturing integration and intelligence solution: case study in global chemical company. J. Softw. 2012, 7(8):1727-1737.

XU, L. D., HE, W., LI, S. Internet of Things in industries: a survey. IEEE Trans. Ind. Inf. 2014, 10(4):2233-2243.

XU, X. W. From cloud computing to cloud manufacturing. Rob. Comput. Integr. Manuf. 2012, 28(1):75-86. 